\title{
Ensino de Geometria e Movimento da Matemática Moderna: uma análise de histórias produzidas nas pesquisas acadêmicas
}

\author{
Teaching of Geometry and Movement of Modern \\ Mathematics: an analysis of stories produced in academic \\ research \\ Enseñanza de la geometría y el movimiento de las \\ matemáticas modernas: un análisis de historias \\ producidas en la investigación académica
}

\author{
Sidnéia Almeida Silva \\ Universidade Estadual de Santa Cruz - UESC, \\ Ilhéus,Bahia, Brasil, \\ E-mail: siasilva@uesc.br \\ Orcid: 0000-0001-5799-4745 \\ Larissa Pinca Sarro Gomes \\ Universidade Estadual de Santa Cruz -UESC \\ Ilhéus, Brasil, \\ E-mail: Ipsgomes@uesc.br \\ Orcid: 0000-0001-6839-6927 \\ Martha Raíssa lane Santana da Silva \\ Universidade Federal de São Paulo -UNIFESP, \\ São Paulo/SP. \\ E-mail: martharaissa@hotmail.com \\ Orcid: 0000-0002-1818-0957
}

Resumo: Este artigo apresenta o mapeamento e análise de pesquisas produzidas no âmbito dos programas brasileiros de pós-graduação stricto sensu, no período de 2000 a 2019, que problematizaram as propostas para o ensino de Geometria em tempos do Movimento da Matemática Moderna. Aspectos importantes do Movimento e das diferentes orientações para o ensino de Geometria foram identificados nas onze dissertações selecionadas, estabelecendo um diálogo com autores que problematizam a cultura escolar em uma perspectiva histórica. Com a análise foi possível identificar uma concentração de pesquisas voltadas para o primeiro ciclo do Ensino Secundário, considerando os livros didáticos e os documentos normativos como as fontes mais utilizadas. Na abordagem da Geometria, destacou-se as transformações geométricas e a ênfase na Geometria intuitiva e dedutiva. Das ausências, foram identificadas poucas construções geométricas, falta de interação com o estudante e de orientações consistentes aos professores e alunos nas coleções de livros didáticos.

Palavras-chave: História da educação matemática. Geometria. Movimento da Matemática Moderna. 
Abstract: This paper presents the mapping and analysis of research produced within the scope of the Brazilian postgraduate programs stricto sensu, in the period from 2000 to 2019, which problematized the proposals for the teaching of Geometry in times of the Modern Mathematics Movement. Important aspects of the Movement and the different orientations for teaching Geometry were identified in the eleven selected dissertations, establishing a dialogue with authors who problematize school culture in a historical perspective. With the analysis it was possible to identify a concentration of research aimed at the first cycle of Secondary Education, considering textbooks and normative documents as the most used sources. In the Geometry approach, the geometric transformations and the emphasis on intuitive and deductive Geometry were highlighted. Of the absences, few geometric constructions were identified, lack of interaction with the student and consistent guidance to teachers and students in the textbook collections.

Keywords: History of mathematical education. Geometry. Modern Mathematics Movement.

Resumen: Este artículo presenta el mapeo y análisis de la investigación producida en el ámbito de los programas de posgrado brasileños stricto sensu, en el período 2000 a 2019, que problematizó las propuestas para la enseñanza de la Geometría en tiempos del Movimiento de la Matemática Moderna. En las once disertaciones seleccionadas se identificaron aspectos importantes del movimiento y las diferentes orientaciones para la enseñanza de la Geometría, estableciendo un diálogo con autores que problematizan la cultura escolar en una perspectiva histórica. Con el análisis fue posible identificar una concentración de investigación dirigida al primer ciclo de Educación Secundaria, considerando los libros de texto y documentos normativos como las fuentes más utilizadas. En el enfoque de Geometría, se destacaron las transformaciones geométricas y el énfasis en la Geometría intuitiva y deductiva. De las ausencias, se identificaron pocas construcciones geométricas, falta de interacción con el alumno y orientación constante a los profesores y alumnos en las colecciones de libros de texto. Palabras- chave: Historia de la educación matemática. Geometría. Movimiento de Matemáticas Modernas.

Recebido em

$08 / 01 / 2021$

Aceito em

$2103 / 2021$ 


\section{Universidade Federal da Grande Dourados}

\section{INTRODUÇÃO}

As produções acadêmicas desenvolvidas no campo da História da educação matemática que se dedicam a problematizar o Movimento internacional, conhecido como Movimento da Matemática Moderna (MMM), permitem compreender diversos aspectos relacionados às propostas de mudanças de conteúdos e metodologias da matemática escolar.

Um inventário dessas produções, elaborado no âmbito do Grupo de Pesquisa de História da Educação Matemática (GHEMAT), foi realizado resultando na localização de mais de cinquenta trabalhos, entre artigos publicados em revistas acadêmicas, dissertações de mestrado e teses de doutorado, sendo trinta deles destinados a discutir propostas para o ensino de Geometria (OLIVEIRA; SILVA; VALENTE, 2011). Os autores argumentaram que o interesse expressivo em se estudar o ensino de Geometria estava relacionado ao projeto de pesquisa intitulado $A$ trajetória da geometria escolar no Brasil e em Portugal e o Movimento da Matemática Escolar'1.

Procurando estabelecer um diálogo com esse inventário, neste artigo temos como objetivo compreender as propostas para o ensino de Geometria, produzidas em tempos do Movimento da Matemática Moderna, apresentadas nas pesquisas desenvolvidas no âmbito dos programas brasileiros de pós-graduação stricto sensu, no período de 2000 a 2019.

Com o estudo em andamento, localizamos o trabalho de Santos e Lando (2020), que se propôs a analisar as teses e dissertações elaboradas no Brasil, com enfoque na abordagem do ensino de Geometria, no contexto do Movimento da Matemática Moderna (MMM), que pode ser analisado nos livros didáticos.

Diferente da proposta das autoras, que apresentaram uma análise das pesquisas que priorizaram os livros didáticos, nossa intenção é compreender as propostas para o ensino de Geometria nos estudos já concluídos, que consideraram diferentes tipos

\footnotetext{
${ }^{1}$ Subprojeto coordenado pela Profa. Maria Célia Leme da Silva que compõem o projeto "A matemática moderna nas escolas de Brasil e Portugal: estudos históricos comparativos, desenvolvido entre 2006 e 2009.
} 


\section{Universidade Federal da Grande Dourados}

de fontes como cadernos escolares, documentos normativos, revistas de ensino, guias de orientações pedagógicas, apostilas, diretrizes curriculares, dentre outros.

O interesse por essa temática surgiu com os estudos realizados no desenvolvimento de uma pesquisa de mestrado ${ }^{2}$, no Programa de Pós-Graduação em Educação em Ciências e Matemática (PPGECM), da Universidade Estadual de Santa Cruz - UESC. Neste contexto, consideramos autores da História Cultural para compreender os discursos educacionais, como resultado de uma construção cultural em articulação com aspectos sociais. Desse modo, temos interesse em "identificar o modo como em diferentes lugares e momentos" o ensino de Geometria foi pensado, construído e implementado (Chartier, 1990, p. 16-17).

O estudo da cultura escolar nos permitiu instigar uma compreensão do âmbito educacional a partir do "conjunto de normas que estabelecem conhecimentos a ensinar e condutas a inculcar, e um conjunto de práticas que permitem a transmissão desses conhecimentos e a incorporação desses comportamentos", conforme evidência Dominique Julia (2001, p. 10).

Entendemos que este trabalho seja de interesse de pesquisadores do campo da História da educação matemática, que buscam compreender as produções vinculadas ao $\mathrm{MMM}$ e as propostas para ensino de Geometria. Pode interessar também à professores de matemática, pois a partir dessas histórias é possível "se relacionar de modo menos fantasioso e mais científico com esse passado", permitindo avaliar as práticas cotidianas no tempo presente (Valente, 2013, p. 28).

Inicialmente, apresentamos alguns aspectos importantes do MMM e das diferentes orientações para o ensino de Geometria, que podem nos ajudar nas interpretações elaboradas ao analisar o corpus deste trabalho.

\section{O EnSinO de GeOMETRIA no Movimento da MATEMÁticA MODERNA}

\footnotetext{
${ }^{2}$ A pesquisa é intitulada "A Geometria no segundo ciclo do Ensino Secundário: uma análise da coleção Matemática produzida na Bahia na década de 1970" com orientação da professora Dra. Larissa Pinca Sarro Gomes e coorientação da professora Dra. Martha Raíssa lane Santana da Silva.
} 
Partindo de acontecimentos externos ao ambiente educacional, destacamos 0 período pós II Guerra Mundial, no qual as competências matemáticas dos estudantes, deveriam atender às necessidades modernas da época, que apresentavam um desenvolvimento considerável nas esferas científica, tecnológica e econômica. O momento exigia mudanças no ensino de matemática e na preparação dos estudantes para o ensino superior (Guimarães, 2007).

De acordo com o autor supracitado, o Movimento que ficou conhecido como MMM, tem sua referência no Seminário de Royaumont, que aconteceu no final da década de 1959, na França, tendo sido organizado pela Organização Europeia de Cooperação Econômica (OECE). Ainda que esse seminário tenha sido reconhecido como o início das ações desse Movimento de modernização, o MMM foi avaliado como "uma série de iniciativas para reforma do ensino escolar da matemática que congregou autoridades educacionais, matemáticos e educadores de diversos países", ocorrendo entre os anos 1950 e 1980 (Dias, 2008, p. 2).

O entendimento do MMM no sentido plural é também evidenciado nos estudos de Garnica e Souza (2012, p. 318), ressaltando os diferentes modos como o MMM "ocorreu numa determinada instituição de ensino, e quais significados podem ter sido atribuídos a essa expressão e tornados, por isso, práticas de ensino vigente e 'materializados' num certo tempo e espaço".

De acordo com Garnica e Souza (2012), no contexto da sala de aula, a ideia do MMM não foi unânime, sendo identificados discursos diferentes ao considerar personagens entendidos como "geradores" das propostas, que se apropriaram de maneira particular das ideias defendidas. É importante considerar também os "professores multiplicadores", que participavam de cursos de preparação específicos do MMM e desenvolviam suas propostas para o ensino de Matemática. Finalmente, os autores mencionam os professores que iriam executar as ideias do Movimento na sala de aula, sem que o movimento tenha sido "consolidado como uma política educacional específica, abraçada integralmente e explicitamente pelo Estado" (Garnica; Souza, 2012, p. 321). 


\section{Universidade Federal da Grande Dourados}

A pluralidade em torno do MMM também se apresentou na proposta para o ensino de Geometria, delineadas no Seminário de Dubrovnik, que aconteceu na lugoslávia, em 1960, considerando as recomendações do Seminário de Royaumont. Na avaliação do Grupo de Estudos do Ensino da Matemática (GEEM)², a proposta tinha influências do ensino realizado em vários países e adaptada "à média de alunos bem-dotados", o que não atendia à realidade de todos, ficando os encaminhamentos do programa para que o ensino de Geometria pudesse ser adequado à realidade de cada país (GEEM, 1965, p. 2).

Considerando que o enfoque do MMM eram as estruturas algébricas, Pavanello (1989, p.163) argumentou que as mudanças com relação às propostas para o ensino da Geometria deveriam ser implementadas "por planos vetoriais ou por transformações".

Essa proposta para o ensino de Geometria é também foco da discussão realizada por Oliveira et al. (2011) ao identificarem duas tendências. A primeira vinculada às ideias de Félix Klein, incorporando as transformações geométricas, e a segunda, estava relacionada à geometria euclidiana com uma abordagem diferente, envolvendo a inclusão de novos axiomas e fazendo uso de uma geometria experimental.

Sobre essa temática, Leme da Silva (2010, p. 85), ressaltou que "é preciso reconhecer e entender porque o percurso do ensino de Geometria é distinto de outros conteúdos matemáticos, como por exemplo, as estruturas algébricas, que mesmo sem domínio dos professores sobre o assunto, são inseridas diretamente nos manuais didáticos".

Assim, dialogando com esses autores apresentamos a seguir o percurso metodológico que nos permitiu compreender as propostas para o ensino de Geometria a partir das histórias produzidas nas pesquisas acadêmicas.

${ }^{3}$ O GEEM foi criado em 1961, formado por autores de livros didáticos e professores de vários segmentos de ensino, seu objetivo era de "[...] incentivar e divulgar o estudo da Matemática Moderna, por meio de cursos de aperfeiçoamento à professores de matemática das escolas secundárias" (Camargo, 2009, p. 49). 


\section{Percurso metodológico}

O processo sistemático de identificação, localização e descrição das pesquisas produzidas em um campo de estudo, para um período de tempo específico, é compreendido por Fiorentini, Passos e Lima (2016) como mapeamento da pesquisa. Tal processo pode fornecer informações mais descritivas dessa produção, como sugerem os autores, e esse é o primeiro movimento a ser realizado nos estudos que se dedicam a mapear pesquisas já concluídas, que estão relacionadas a um determinado tema de interesse.

Após esse primeiro movimento, uma leitura mais detalhada do corpus da pesquisa permite um exercício de escrita considerando tanto aspectos mais descritivos quanto analíticos dos trabalhos encontrados no processo de mapeamento. A partir desses encaminhamentos, apresentamos na Figura 1, o delineamento da pesquisa neste artigo.

\begin{tabular}{|c|}
\hline Busca pelas palavras-chave \\
\hline Levantamento de Dados \\
\hline Identificação e seleção dos que touxeram os pressupostos desta \\
investigação
\end{tabular}

Figura 1 Delineamento da pesquisa Fonte: Construção das autoras

A primeira etapa foi destinada à busca pelos trabalhos, que ocorreu no Catálogo de Teses e Dissertações do Portal CAPES. Para esse levantamento foram utilizados os termos "Geometria" e "Movimento da Matemática Moderna", escritos entre aspas e separados pelo operador booleano ${ }^{4}$ AND. A escolha desse operador ocorreu para

\footnotetext{
${ }^{4}$ Os operadores booleanos AND, OR e NOT são utilizados para facilitar a seleção das informações desejadas nem levantamentos bibliográficos em bases de dados, a utilização ocorre nas seguintes
} 
"restringir a pesquisa, fazendo a intersecção dos conjuntos de trabalhos que possuem os termos combinados" (Pizzani; Bello; Hayashi, 2012, p. 61).

No levantamento dos dados foram localizados 28 estudos. Após a leitura de seus resumos, foram identificados e selecionados onze trabalhos (Quadro 1), de modo que atendesse a proposta desta pesquisa, ou seja, que trouxesse a discussão sobre propostas para o ensino de Geometria em documentos produzidos em tempos do MMM. Os documentos são entendidos aqui como as fontes utilizadas pelos autores das teses e dissertações, incluindo livros didáticos, guias de orientações pedagógicas, cadernos escolares, revistas, programas, currículos, depoimentos, dentre outros, que permitiram aos pesquisadores identificar propostas para o ensino de Geometria.

Atenderam a esse critério, as dissertações de mestrado, conforme Quadro 1, organizado com seus respectivos autores, ano de publicação e títulos. Algumas dessas pesquisas apresentam um recorte temporal mais amplo que o de interesse desta investigação, e para esses casos, foram considerados apenas os resultados referentes à Geometria proposta em tempos do $\mathrm{MMM}$, mais precisamente nas décadas de 1960 e 1970.

Quadro 1 Autores, ano de publicação e títulos.

\begin{tabular}{|c|c|}
\hline Autor/Ano & Título \\
\hline Fraga (2004) & $\begin{array}{l}\text { Um estudo sobre Triângulos em livros didáticos a partir do Movimento da } \\
\text { Matemática Moderna }\end{array}$ \\
\hline Ferreira (2006) & $\begin{array}{l}\text { Propostas pedagógicas de Geometria no movimento paranaense de } \\
\text { Matemática Moderna }\end{array}$ \\
\hline Britto (2008) & $\begin{array}{l}\text { Scipione Di Pierro Neto e sua proposta para o ensino da Geometria na } \\
\text { coleção Curso Colegial Moderno }\end{array}$ \\
\hline Ferreira (2008) & $\begin{array}{l}\text { Orientações curriculares para o ensino de Geometria: do período da } \\
\text { Matemática Moderna ao momento atual }\end{array}$ \\
\hline Camargo (2009) & $\begin{array}{l}\text { O ensino da Geometria nas coleções didáticas em tempos do Movimento } \\
\text { da Matemática Moderna na capital da Bahia }\end{array}$ \\
\hline Brigo (2010) & $\begin{array}{l}\text { As Figuras Geométricas no ensino de matemática: uma análise histórica } \\
\text { nos livros didáticos }\end{array}$ \\
\hline Rios (2010) & A proposta de ensino da Geometria nos livros do GRUEMA \\
\hline Rocco (2010) & $\begin{array}{l}\text { Práticas e discursos: análise histórica dos materiais didáticos no ensino } \\
\text { de Geometria }\end{array}$ \\
\hline
\end{tabular}

situações, AND para restringir a pesquisa, OR para agrupar os termos e NOT para excluir um assunto da expressão de busca (Pizzani; Bello; Hayashi, 2012). 


\begin{tabular}{|l|l|}
\hline Silva (2014) & $\begin{array}{l}\text { As Transformações Geométricas nos currículos prescritos de matemática } \\
\text { no Ensino Fundamental (1930-2010) }\end{array}$ \\
\hline $\begin{array}{l}\text { Valentim Júnior } \\
\text { (2013) }\end{array}$ & $\begin{array}{l}\text { A Geometria Analítica como conteúdo do ensino Secundário: análise dos } \\
\text { livros didáticos utilizados entre A Reforma Capanema e o MMM }\end{array}$ \\
\hline $\begin{array}{l}\text { Mendonça } \\
(2016)\end{array}$ & Que Geometria ensinar às crianças em tempos de Matemática Moderna? \\
\hline
\end{tabular}

Fonte: Elaborado pelas autoras.

Após esse movimento, realizamos a leitura e fichamento dos trabalhos, considerando o período, o local, as fontes utilizadas e os segmentos de ensino a qual se destinavam. Concluída essa etapa, classificamos e organizamos esses dados por segmentos de ensino (Quadro 2), e em seguida analisamos as propostas para 0 ensino de Geometria atentas a questões como: o espaço ocupado pela Geometria; como os conceitos geométricos foram apresentados; suas formas de abordagem utilizando a observação, experimentação, as transformações geométricas ou algum material manipulativo; se a proposta era pelo método intuitivo ou dedutivo ${ }^{5}$.

Essas questões foram condutoras no sentido de compreender como as fontes foram interrogadas pelos pesquisadores, no sentido que propõe Julia (2011, p. 19), analisando as normas que regem a escola e orientam o ensino, considerando o papel desempenhado pelo professor, como também "dos conteúdos ensinados e das práticas escolares".

\section{Propostas PARA O ENSINO DE GEOMETRIA PRODUZIDAS DURANTE O MMM}

Tendo em vista os segmentos de ensino e os documentos ${ }^{6}$ utilizados pelos pesquisadores, na compreensão de propostas para o ensino de Geometria, a análise

\footnotetext{
${ }^{5}$ A Geometria pelo método intuitivo ocorre a partir da manipulação de objetos com objetivo "[...] de criar condições materiais circunstanciais para que o fato a ser estudado se realize e permita tirar conclusões" (Rios, 2010, p. 116). Por outro lado, o estudo da Geometria pelo método dedutivo se baseia "[...] em axiomas, postulados e definições, a partir dos quais, com um encadeamento lógico, se demonstram teoremas, que passam a ser considerados verdadeiros e com estes podem ser demonstrados outros teoremas" (Rios, 2010, p. 116)

${ }^{6}$ Esses documentos são os que trazem discussão sobre a Geometria nas décadas de 1960 e 1970, alguns trabalhos trazem documentos que são referentes a outro momento histórico, como o caso de Silva (2014), que também analisa manuais Experiências Matemáticas da Proposta Curricular de Matemática (1988), momento posterior ao período de interesse desta pesquisa.
} 
se iniciou com uma separação dos trabalhos. Foram considerados aqueles que tinham a intenção de compreender as propostas para o ensino de Geometria no Ensino Primário ${ }^{7}$ e aqueles destinados ao primeiro e segundo ciclos do Ensino Secundário, conforme Quadro 2. Em seguida, as pesquisas foram organizadas de modo a destacar os documentos analisados e o local de referência.

Quadro 2 Seguimentos de ensino, autores, fontes e local.

\begin{tabular}{|c|c|c|c|c|c|c|c|c|c|c|c|}
\hline \multirow{2}{*}{\multicolumn{2}{|c|}{$\begin{array}{l}\text { egmento } \\
\text { de ensino }\end{array}$}} & \multirow[b]{2}{*}{ Autores } & \multicolumn{8}{|c|}{ Documentos analisados } & \multirow[b]{2}{*}{ Local } \\
\hline & & & $\begin{array}{l}\text { Livro } \\
\text { didático }\end{array}$ & $\begin{array}{l}\text { Manual } \\
\text { pedagógic }\end{array}$ & Caderno & Prova & $\begin{array}{c}\text { Revist } \\
\text { a }\end{array}$ & Apostila & $\begin{array}{c}\text { Document } \\
0 \\
\text { normativo }\end{array}$ & $\begin{array}{l}\text { Entrevista/ } \\
\text { depoimentc }\end{array}$ & \\
\hline \multicolumn{2}{|c|}{$\begin{array}{l}\text { Ensino } \\
\text { Primário }\end{array}$} & $\begin{array}{l}\text { Mendonç } \\
\text { a (2016) }\end{array}$ & $x$ & & $x$ & & $x$ & & $x$ & & $\begin{array}{l}\text { Minas } \\
\text { Gerais }\end{array}$ \\
\hline \multirow{10}{*}{ 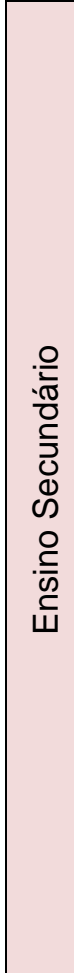 } & \multirow{8}{*}{$\begin{array}{l}\text { 음 } \\
.0 \\
\text { ol } \\
\frac{1}{1}\end{array}$} & $\begin{array}{l}\text { Fraga } \\
(2004)\end{array}$ & $x$ & & & & & & & & $\begin{array}{l}\text { Espírit } \\
0 \\
\text { Santo }\end{array}$ \\
\hline & & $\begin{array}{l}\text { Ferreira } \\
(2006)\end{array}$ & $x$ & & & $\mathrm{X}$ & & $x$ & $x$ & & $\begin{array}{l}\text { Paran } \\
\text { á }\end{array}$ \\
\hline & & $\begin{array}{l}\text { Ferreira } \\
(2008)\end{array}$ & $x$ & & & & & & $\mathrm{x}$ & & $\begin{array}{l}\text { São } \\
\text { Paulo }\end{array}$ \\
\hline & & $\begin{array}{l}\text { Camargo } \\
(2009)\end{array}$ & $x$ & & & & & & & & Bahia \\
\hline & & $\begin{array}{l}\text { Brigo } \\
(2010)\end{array}$ & $x$ & & & & & & $x$ & & $\begin{array}{l}\text { Santa } \\
\text { Catarin } \\
\text { a }\end{array}$ \\
\hline & & $\begin{array}{l}\text { Rios } \\
(2010)\end{array}$ & $x$ & $\mathrm{x}$ & & & & & & & $\begin{array}{l}\text { São } \\
\text { Paulo }\end{array}$ \\
\hline & & $\begin{array}{l}\text { Rocco } \\
(2010)\end{array}$ & & & & & & & $x$ & $x$ & $\begin{array}{l}\text { Santa } \\
\text { Catarin } \\
\text { a }\end{array}$ \\
\hline & & $\begin{array}{l}\text { Silva } \\
(2014)\end{array}$ & & & & & & & $\mathrm{x}$ & & $\begin{array}{l}\text { São } \\
\text { Paulo }\end{array}$ \\
\hline & \multirow{2}{*}{$\begin{array}{l}\text { 을 } \\
\text { OU } \\
\text { OI }\end{array}$} & $\begin{array}{l}\text { Britto } \\
(2008)\end{array}$ & $x$ & & & & & & & $x$ & $\begin{array}{l}\text { São } \\
\text { Paulo }\end{array}$ \\
\hline & & $\begin{array}{l}\text { Valentim } \\
\text { Júnior } \\
\text { (2013) }\end{array}$ & $x$ & & & & & & & & $\begin{array}{l}\text { Minas } \\
\text { Gerais }\end{array}$ \\
\hline
\end{tabular}

Fonte: Elaborado pelas autoras.

${ }^{7}$ O programa proposto para o ensino de Geometria durante o MMM estava dividido entre primeiro ciclo para estudantes com idades entre 11 e 15 anos e o segundo ciclo para estudantes de 15 a 18 anos GEEM (1965, p. 4). No Brasil, de acordo com a Lei de Diretrizes e Bases ํ‥ 4024, de 20 de dezembro de 1961, o Ensino Primário era obrigatório a partir dos sete anos e ministrado, em quatro séries anuais no mínimo, em relação ao Ensino Secundário, o ciclo ginasial tinha duração de quatro séries anuais e o ciclo colegial, de três séries no mínimo. A partir Lei n5.692, de 11 de agosto de 1971, há mudanças na nomenclatura, o que Ensino Primário e ciclo ginasial passa a ser $1^{\circ}$ grau e obrigatório compreendendo as idades entre 7 e 14 anos e o ciclo colegial passa a ser o $2^{\circ}$ grau. 


\section{Universidade Federal da Grande Dourados}

Nas pesquisas históricas localizadas, os documentos possuem naturezas diversas, podendo ser os "[...] produzidos por agentes do poder estatal, como programas curriculares, legislação, relatórios de inspetores escolares aos manuais didáticos e artigos de revistas educacionais produzidos por intelectuais e professores", como também "[...] os livros didáticos e demais materiais da indústria cultural" (Bittencourt, 2011, p. 91).

Os livros didáticos aparecem como fonte em muitas pesquisas (Quadro 2), sendo considerados como instrumento precursor das ideias defendidas pelo MMM, pois alcançavam os locais mais afastados, facilitando a aproximação com professores e impactando de forma direta na sala de aula (Oliveira et al., 2011). Além disso, era por meio desses livros didáticos que se materializavam as apropriações dos autores de livros em relação ao movimento. Esse termo apropriação está sento utilizado porque a produção desses autores resulta em "[...] uma história social das interpretações, remetidas para as suas determinações fundamentais (que são sociais, institucionais, culturais) " (Chartier, 1990, p. 26).

Da mesma forma, os documentos normativos também se mostraram fundamentais para uma pesquisa histórica, ainda que não sejam explicitamente citados como fontes privilegiadas em algumas delas, mas são importantes para a compreensão de como a educação é pensada em diferentes momentos históricos e de que modo se busca ordenar a sua prática (Valente, 2013).

Com relação ao segmento de ensino, os estudos se concentraram no Ensino Secundário, com oito trabalhos voltados para $01^{\circ}$ ciclo e apenas dois destinados ao $2^{\circ}$ ciclo. Apenas o trabalho de Mendonça (2016) teve como proposta investigar a presença da Geometria, em termos de conteúdos e métodos, no Ensino Primário em Minas Gerais, na cidade de Juiz de Fora. O estudo ficou delimitado às décadas de 1960 e 1970, quando se discutiam as ideias do MMM no país. De forma geral, os documentos e materiais analisados pelo autor revelaram um distanciamento das propostas para o ensino de Geometria na perspectiva da Matemática Moderna, sendo "mais evidentes as influências de vagas pedagógicas já consolidadas, que conferiam 


\section{Universidade Federal da Grande Dourados}

à observação o papel central na aprendizagem de Geometria pelas crianças" (Mendonça, 2016, p. 7).

$\mathrm{O}$ que pode ter influenciado os pesquisadores a se debruçarem mais em relação a um segmento de ensino do que em outros? Estaria relacionado à disponibilidade das fontes? As discussões sobre o ensino de Geometria estariam mais consolidadas no $1^{\text {}}$ ciclo, conhecido como ginasial?

A concentração de trabalhos no primeiro ciclo do Ensino Secundário corrobora com o inventário realizado pelo GHEMAT, a respeito dos estudos do MMM. Nesse inventário, se destaca também que as pesquisas dedicadas ao Ensino Primário procuraram compreender os debates relacionados às metodologias para o ensino de matemática e os processos de ensino, considerando as ideias de Piaget (Oliveira, et al., 2011).

Essa mesma questão também aparece nos estudos de Garnica e Souza (2012) quando mencionam o trabalho de Soares (2001) e salientam que a Matemática Moderna, inicialmente, apresentava um projeto para o Ensino Secundário, mas que havia um outro posicionamento de que o Ensino Primário seria o segmento de ensino ideal para aplicar as novas propostas tendo em vista a "ausência de vícios".

\section{HISTÓRIAS E PROPOSTAS PARA O ENSINO DE GEOMETRIA NO 1응 CICLO DO ENSINO SECUNDÁRIO}

A análise dos trabalhos permitiu identificar o protagonismo que tinham os livros didáticos produzidos por professores, organizados em Grupos de Estudos, em diversas regiões brasileiras.

Os livros didáticos da coleção Ensino atualizado da matemática para o $1^{\circ}$ ciclo foi uma dessas produções. Publicado pela editora EDART e elaborado pelo grupo de professores baianos no Centro de Ensino de Ciências da Bahia (CECIBA), na década de 1970, a coleção foi privilegiada para análise nas pesquisas de Fraga (2004), Camargo (2009) e Brigo (2010). 
Outra produção didática produzida em tempos do MMM ocorreu pelo Núcleo de Estudo e Difusão do Ensino de Matemática (NEDEM), em Curitiba. Na avaliação de Ferreira (2006), a Geometria apresentada nos livros didáticos elaborados pelo grupo paranaense ocorreu de forma direta, fazendo uso de uma linguagem técnica e formal, com ênfase na teoria, sem interação com o estudante. Os conteúdos antecedem os exercícios que "são poucos, geralmente interrogativos e de cálculos, possuindo poucas situações-problema sem contextualização". Também aparecem poucas construções geométricas para o uso de régua e compasso e não se identificam "orientações práticas para compreensão de figuras semelhantes e outros conteúdos" (Ferreira, 2006, p. 103). No entanto, a autora afirma que o grupo foi ousado em trabalhar com as operações de vetores e a demonstração de teoremas a partir da geometria vetorial, fato que foi evidenciado também no inventário apresentado por Oliveira et al. (2011).

O trabalho com vetores e com as transformações geométricas também ganhou destaque na coleção Ensino Atualizado, produzida na Bahia, em 1975, conforme ressaltou Camargo (2009). Ainda segundo Brigo, nessa coleção há um destaque para o ensino de uma geometria dedutiva, com valorização da figura geométrica e predominância da discussão de conteúdos da Geometria Afim e da Geometria Euclidiana, quando comparada com a Álgebra e a Aritmética (Brigo, 2010).

A coleção de autoria de Catunda et.al. (1975) utilizou a geometria das transformações de maneira intensa e os casos de congruência de triângulos são obtidos por meio da geometria das transformações. Tal fato também foi ressaltado na pesquisa de Fraga (2004, p.50), que justificou a análise da coleção do grupo de professores da Bahia - apesar de não ter sido muito utilizada nas escolas do Espírito Santo, estado no qual realizou sua pesquisa - "como uma das poucas que trabalhou a geometria das transformações, seguindo o programa proposto para o ensino de geometria" no período por ele estudado.

Até o momento, os resultados das pesquisas têm evidenciado que o ensino de Geometria pelas transformações geométricas se destacou como uma proposta inovadora do MMM, e muitos autores tentaram implementá-la em suas produções 


\section{Universidade Federal da Grande Dourados}

didáticas. A respeito desse tema, Silva (2014) ressaltou que não havia orientações consistentes nas coleções de manuais didáticos para os professores ensinarem Geometria utilizando operações com vetores, mas faz uma ressalva em relação aos trabalhos desenvolvidos pelo grupo baiano coordenado pela Professora Martha Dantas e Omar Catunda.

A singularidade da produção do grupo se fundamenta no fato de que, no contexto das escolas secundárias no Brasil, apenas o grupo da Bahia "que realmente procurou inserir o ensino das transformações nas práticas dos docentes por meio das coleções de manuais produzidas por esse grupo nas décadas de 70 e 80" (Silva, 2014, p. 89). A autora acrescentou que outros autores tiveram a iniciativa de abordar a Geometria por transformações, mas foram atividades isoladas, que não conseguiram modificar de forma significativa o ensino da Geometria nesse segmento de ensino.

Na avaliação de Fraga (2004, p. 73), outro destaque em relação aos livros desse período é a falta de contextualização dos conteúdos: "onde o aluno não consegue fazer a conexão com algo já visto e também não é conduzido a uma experimentação". Por outro lado, as demonstrações aparecem em todos os livros desse período, como forma de possibilitar que o aluno desenvolva um raciocínio lógico dedutivo, com a proposição de exercícios que direcionavam os estudantes a realizarem demonstrações apoiadas em propriedades já estudadas.

Diferente do que observou Fraga (2004), a respeito das abordagens metodológicas do ensino de Geometria, Rios (2010) ressaltou "que havia um consenso de que o ensino deveria ocorrer primeiro mediante experimentações e observações realizadas pelo aluno e só depois ser introduzida a geometria dedutiva" (Rios, 2010, p. 153).

Em termos metodológicos, Rios (2010) identificou aproximações entre a coleção Curso Moderno de Matemática para o ensino de primeiro grau, de autoria de Lucília Bechara, Manhúcia Liberman e Anna Franchi e as propostas defendidas por George Papy, Lucienne Felix, Zoltan Dienes - autores que participaram ativamente dos fóruns científicos internacionais em tempos do MMM. A coleção analisada por Rios (2010) foi produzida no interior do Grupo de Ensino de Matemática Atualizada (GRUEMA), em São Paulo. 
A metodologia observada por Rios, nas produções do GRUEMA, considera a participação do aluno na construção dos conceitos sendo motivado e provocado a realizar construções geométricas, a organizar informações, responder questionamentos com a finalidade de compreender propriedades e definições. Tais características, segundo Rios, revelam apropriação das autoras da coleção com as ideias de Choquet (1961), Dieudonné (1961), Fehr (1966) e Piaget (1961).

Quanto aos materiais didáticos indicados para o ensino de Geometria eles são mais evidenciados na pesquisa de Rocco (2010), os quais foram localizados a partir da análise de documentos normativos das décadas de 1960 e 1970, do estado de Santa Catarina. Na avaliação da autora, ficou evidente o formalismo moderno e o tecnicismo, com indicações para elaborar e utilizar materiais didáticos como o algebloc, as técnicas de dobraduras, massa de modelar, jogos, régua, compasso e esquadro, no contexto das transformações geométricas.

A autora também acrescenta que "a manipulação dos materiais deveria proporcionar a descoberta das estruturas matemáticas" no intuito de facilitar a "passagem do concreto ao abstrato desenvolvendo com isso um raciocínio lógico da Matemática" (Rocco, 2010, p. 81). No entanto, ao confrontar os documentos normativos com os depoimentos de professores, a autora percebeu um distanciamento entre o discurso observado nos documentos e o discurso dos professores sobre a prática em sala de aula.

A partir das análises dessas pesquisas já concluídas, foi possível identificar a pluralidade de propostas para o ensino de Geometria e as apropriações das ideias modernistas, principalmente nos documentos normativos e livros didáticos, com poucas discussões a respeito das práticas no cotidiano escolar.

\section{O ENSINO DE GEOMETRIA NO 2 CICLO DO ENSINO SECUNDÁRIO, AS TRANSFORMAÇÕES GEOMÉTRICAS, O TRATAMENTO ALGÉBRICO E AS FIGURAS}


Das propostas para o ensino de Geometria no $2^{\circ}$ ciclo do Ensino Secundário, as duas pesquisas localizadas, evidenciaram distanciamento das propostas do MMM, como também a presença das transformações geométricas, das estruturas algébricas e figuras na compreensão de conceitos.

Na pesquisa de Britto (2008) foi privilegiada como fonte a coleção Curso Colegial Moderno, publicada no final da década de 1960, produzida pelo professor Scipione Di Pierro Neto em parceria com Ruy Madsen Barbosa e Luiz Mauro Rocha.

Observamos algumas diferenças na abordagem da Geometria nos três volumes analisados pela autora, no primeiro volume da coleção, aborda-se a Geometria Euclidiana, acompanhada de exercícios com algumas demonstrações de teoremas; no segundo volume, a Geometria aparece na última parte do livro, dividida em cinco capítulos envolvendo a Transformações Geométricas dentre os temas apresentados. Britto (2008) anuncia que as transformações geométricas foram utilizadas na definição dos sólidos geométricos, entretanto, ao observarmos as figuras usadas na pesquisa, não foi possível depreender isso, pois não é feita a construção geométrica, havendo uma predominância da álgebra e das definições.

Com respeito ao segundo volume, Britto (2008) sinaliza também a preocupação dos autores na apresentação dos conteúdos, sobretudo das figuras, por serem bem desenhadas e seguidas de textos explicativos, o que poderia colaborar para melhor compreensão por parte dos estudantes. Não foi intenção da autora analisar o terceiro volume como fez nos volumes anteriores, na breve explanação que faz, afirma que será feito "o estudo de Geometria Analítica e Transformações Geométricas como uma continuidade ao primeiro volume apoiada na Teoria das Matrizes" (Britto, 2008, p. 115).

A Geometria Analítica é foco da pesquisa de Valentim Júnior (2013), da qual foram considerados os resultados referentes às décadas de 1960 e 1970. O autor destaca os livros didáticos sem adesão à proposta para o ensino de Geometria orientadas pelo MMM, sendo eles as edições $12^{\mathrm{a}}$ e $16^{\mathrm{a}}$ de Matemática: terceiro ano colegial de Ary Quintella, com publicação em 1965 e 1968 e o livro Curso de matemática: para os 


\section{Universidade Federal da Grande Dourados}

primeiro, segundo e terceiro anos dos cursos Clássico e Científico de Manoel Jairo Bezerra de 1960.

Por outro lado, Valentim Júnior (2013) discute outros livros que contemplaram o ideário do MMM, por exemplo, o terceiro volume Matemática na Escola Renovada de Scipione di Pierro Netto e Célia Contin Góes, publicado em 1972, no qual, no estudo da Geometria Analítica, são apresentados todos seus elementos para o Ensino Secundário, com quase 100 exercícios envolvendo as propriedades e aplicações e algumas demonstrações; e o livro Matemática: curso colegial moderno de Luiz Mauro Rocha e Ruy Madsen Barbosa, com publicação de 1970, que explora a geometria das transformações por meio da translação, simetria, rotação e homotetia apoiadas nas estruturas. Além disso destaca-se a presença das estruturas algébricas e um reduzido tratamento gráfico, no qual a geometria analítica é explorada de forma basicamente algébrica (Valentim Júnior, 2013).

Observamos que proposta para o ensino da Geometria Analítica por processos algébricos, também é evidenciada quando Valentim Júnior (2013) analisou o livro de Matemática, $3^{\text {a }}$ série, de Gelson lezzi e outros autores, publicado em 1974. No estudo da circunferência e da reta, por exemplo, lezzi et al. (1974) faz uso de tratamento algébrico e de figuras. Essa obra se diferencia das demais pela tentativa de reduzir ao mínimo possível a formalização, apresentando progressos gráficos, e o pioneirismo com o emprego das primeiras figuras coloridas (Valentim Júnior, 2013).

\section{CONSIDERAÇÕES FINAIS}

Analisando as histórias produzidas nas pesquisas acadêmicas com foco na Geometria, no período que compreende o MMM, percebemos questões importantes com relação ao ensino dessa rubrica escolar, em termos de proposição de conteúdos, abordagem metodológica, recurso a materiais didáticos, representação gráfica etc.

As pesquisas tomaram como foco de análise, majoritariamente, o primeiro ciclo do Ensino Secundário, em detrimento do segundo ciclo do Secundário e do Ensino Primário, ficando a inquietação sobre as razões que justifiquem o desfalque nesses 
segmentos de ensino, que não foram tão contemplados com as investigações. Entre os documentos analisados, os livros didáticos e os documentos normativos foram os mais utilizados nas investigações, conforme análise a partir do Quadro 1.

Os livros didáticos como principal fonte das pesquisas reafirma o fato de eles serem importantes colaboradores do movimento, uma vez que tais documentos foram os que mais disseminaram o MMM. Uma parte considerável desses livros estão associados às produções de forma coletiva e no contexto de grupos coordenados por professores, embora também encontramos produções individuais.

Com relação aos documentos normativos, encontramos aqueles referentes aos estados de Minas Gerais, Paraná, São Paulo e Santa Catarina. E a partir dos resultados ficou evidente que o MMM foi reinventado nos locais por onde circulou. Até mesmo em pesquisas realizadas em um mesmo estado foi possível encontrarmos diferenças nas propostas para o ensino de Geometria.

Podemos afirmar que há uma concentração de estudos nas regiões Sul e Sudeste, com ausências nas regiões Norte, Nordeste e Centro-Oeste. No entanto, em se tratando do Nordeste, embora não haja documentos normativos estaduais com orientações quanto à incorporação das ideias defendidas no MMM, há produção de materiais didáticos na Bahia, no contexto do CECIBA. Por mais que não houvesse uma política educacional explícita no referido estado, havia um grupo de professores mobilizados nesse sentido, inclusive a produção desse grupo esteve presente em diferentes localidades além da Bahia, como Santa Catarina e Espírito Santo. O destaque feito ao grupo ocorre também em relação ao espaço ocupado pela Geometria, na qual predominava a Geometria Afim e a Geometria Euclidiana, o que difere de outras produções da época em que a Geometria nem sempre foi priorizada, em alguns casos só aparecendo ao final dos livros.

Em alguns casos a Geometria era abordada separada da Álgebra e possuía menos destaque, mas também identificamos casos em que aparecia articulada com outros campos de estudo da Matemática. Na maioria dos trabalhos a Geometria foi analisada como um todo, com exceção da pesquisa de Fraga (2004), com o tema de Triângulos, 


\section{Universidade Federal da Grande Dourados}

Brigo (2010), com a análise de Figuras geométricas e Valentim Júnior (2013), com a Geometria Analítica.

Os manuais pedagógicos, também chamados de guia ou manual para o professor, com orientações para o uso dos livros didáticos, foram utilizados como fonte apenas na pesquisa de Rios (2010), em particular, no guia do professor que acompanhava os livros da coleção GRUEMA. Em muitas pesquisas aparece o termo guia e manuais, no entanto, são referentes a documentos normativos, com orientações mais gerais sobre o ensino de Matemática e não sobre como o professor poderia utilizar um livro didático específico.

Encontramos também pesquisas que se valeram de outros documentos, contudo em menor quantidade do que os anteriores. Dentre eles temos revistas, cadernos, provas, apostilas para professores, entrevistas e depoimentos. Notamos que essas fontes foram pouco exploradas na compreensão de propostas para o ensino de Geometria durante o MMM. Contudo, no diálogo entre os documentos normativos e os depoimentos dos professores se evidenciou um distanciamento entre as propostas para o ensino de Geometria e a prática em sala de aula.

As formas de abordar a Geometria se destacou com as transformações geométricas e pela relação entre a Geometria intuitiva, experimental e dedutiva, ora partindo da Geometria intuitiva para a dedutiva, ora apenas dedutiva. Mesmo que as transformações geométricas tenham sido enfatizadas nas pesquisas, como proposta para o ensino de Geometria, Fraga (2004), Camargo (2009) e Silva (2014) afirmam que apenas a proposta apresentada pelo grupo baiano, coordenando por Omar Catunda e Martha Dantas, apresentaram de fato uma inovação com a proposta para o ensino da Geometria desse período.

Observamos também outras abordagens envolvendo a Geometria como foco na conceituação, fazendo uso da linguagem técnica e formal, com ênfase na teoria e no formalismo. Em particular, ressaltamos o estudo da Geometria com ênfase em: demonstrações, tratamento de vetores, construções geométricas, construção em cartolina de triângulos e manuseio através dos movimentos de translação e rotação, uso de figuras geométricas por experimentação para a construção de conceitos, 


\section{Universidade Federal da Grande Dourados}

manipulação de materiais para a exploração das estruturas matemáticas e estudo da Geometria sob aspectos topológicos, Geometria explorada de forma algébrica com experimentações e observações realizadas pelos alunos. Ao mesmo tempo destacam-se algumas ausências, como as poucas construções geométricas e a falta de interação com o estudante.

Alguns materiais apareceram na abordagem da Geometria como o uso de cartolina, régua, compasso, esquadros e transferidor. Também ficou evidente orientações para elaborar e utilizar materiais didáticos como algebloc, massa de modelar, jogos e técnicas de dobradura. Em alguns casos os exercícios foram pouco explorados, geralmente interrogativos e de cálculos, possuindo poucas situaçõesproblema e sem contextualização. Só foi possível perceber a proposta de interação com os estudantes em poucos estudos, por meio do incentivo às experimentações e observações dos estudantes.

\section{AGRADECIMENTOS}

O presente trabalho foi realizado com apoio da Coordenação de Aperfeiçoamento de Pessoal de Nível Superior - Brasil (CAPES).

\section{REFERÊNCIAS}

Bittencourt, C. M. F. (2011). Abordagens Históricas Sobre a História Escolar. Educação \& Realidade, v. 36, n.1, pp. 83-104, janeiro 2011.

Brigo, J. (2010). As Figuras geométricas no ensino de matemática: uma análise histórica nos livros didáticos. (Dissertação de Mestrado). Universidade Federal de Santa Catarina, Florianópolis, Santa Catarina, Brasil.

Britto, L. P. de. (2008). Scipione Di Pierro Neto e sua proposta para o ensino da geometria na Coleção Curso Colegial Moderno. (Dissertação de mestrado). Pontifícia Universidade Católica de São Paulo, São Paulo, Brasil.

Camargo, K. C. (2009). O ensino da geometria nas coleções didáticas em tempos do Movimento da Matemática Moderna na capital da Bahia. (Dissertação de Mestrado). Universidade Bandeirante, São Paulo, São Paulo, Brasil. 
Caldatto, M., \& Pavanello, R. (2015). Um panorama histórico do ensino de geometria no Brasil: de 1500 até os dias atuais. Quadrante, 24(1), 103-128. Obtido de https://quadrante.apm.pt/index.php/quadrante/article/view/63

Chervel, A. (1990) História das disciplinas escolares: reflexões sobre um campo de pesquisa. In: Teoria \& Educação, Porto Alegre, no 2, p. 177-229.

Dias, A. L. M. (2008). O movimento da matemática moderna: uma rede internacional científica-pedagógica no período da Guerra Fria. In; Jornadas LatinoAmericanas de Estudos Sociais das Ciências e das Tecnologias, 2008. Anais. Rio de Janeiro: Núcleo de Computação Eletrônica da UFRJ. Disponível em http://www.necso.ufrj.br/esocite2008/trabalhos/35892.doc.

Ferreira, A. C. da C. (2006). Propostas pedagógicas de geometria no movimento paranaense de matemática moderna. Dissertação de Mestrado em Educação.

Curitiba: Pontifícia Universidade Católica.

Ferreira, R. C. (2008). Orientações curriculares para o ensino de geometria: do período da Matemática Moderna ao momento atual. (Dissertação de Mestrado).

Pontifícia Universidade Católica de São Paulo, São Paulo, Brasil.

Fiorentini, D., Passos, C. L. B. \& Lima, R. C. R. (Ed.). (2016) Mapeamento da pesquisa acadêmica brasileira sobre o professor que ensina Matemática: Período 2001 a 2012. Campinas: FE-Unicamp.

Fraga, S. A. (2004). Um estudo sobre triângulos em livros didáticos a partir do Movimento da Matemática Moderna. (Dissertação de Mestrado). Universidade Federal do Espírito Santo. Vitória, Espírito Santo, Brasil.

Garnica, A. V. M.. \& Souza, L. A. (2012) Elementos de História da Educação Matemática. São Paulo: Cultura Acadêmica/ Editora Unesp.

Gomes, L. P. S. (2014) Entre a Exposição e a Descoberta: a coleção Matemática e as práticas escolares relacionadas à sua utilização no Instituto Nossa Senhora da Piedade. (Tese Doutorado). Universidade Estadual de Campinas, Campinas, São Paulo, Brasil.

Guimarães, H. M. (2007). Por uma matemática nova nas escolas secundárias: perspectivas e orientações curriculares da matemática moderna. In: Matos, J. M. \& Valente, W. R. (Eds.) A matemática moderna nas escolas do Brasil e de Portugal: primeiros estudos (pp. 21-45). São Paulo: Grices/Da Vinci. 
Lei no 4.024, de 20 de dezembro de 1961. (1961). Fixa as Diretrizes e Bases da Educação Nacional. Diário Oficial da União. Brasília, DF: Coleção de Leis do Brasil. Disponível em < https://www2.camara.leg.br>.

Lei $n^{\circ}$ 5.692, de 11 de agosto de 1971. Fixa Diretrizes e Bases para o ensino de $1^{\circ} \mathrm{e}$ $2^{\circ}$ graus, e dá outras providências. Diário Oficial da União. Brasília, DF: Coleção de Leis do Brasil Disponível em < https://www2.camara.leg.br>.

Oliveira, M. C. A., Silva, M. C. L., \& Valente, W. R. (Org.). (2011). O Movimento da matemática moderna: história de uma revolução curricular. Juiz de Fora: UFJF.

Oliveira Filho, F., 2009. O School Mathematics Study Group (SMSG) E O Movimento Da Matemática Moderna No Brasil. (Dissertação de Mestrado). Universidade Bandeirante de São Paulo, SP, Brasil.

Pavanello, R. M. (1989). O Abandono Do Ensino De Geometria: Uma Visão Histórica. Mestrado. Universidade Estadual de Campinas.

Pizzani, L., Silva, R. C. da, Bello, S. F., \& Hayashi, M. C. P. I. (2012). A arte da pesquisa bibliográfica na busca do conhecimento. RDBCl: Revista Digital De Biblioteconomia E Ciência Da Informação, 10(2), 53-66. https://doi.org/10.20396/rdbci.v10i1.1896.

Rios, M. S. B. (2010). A proposta de ensino da geometria nos livros do GRUEMA.

(Dissertação de Mestrado). Universidade Bandeirante de São Paulo, São Paulo, São Paulo, Brasil.

Rocco, C. M. K. (2010). Práticas e discursos: análise histórica dos materiais didáticos no ensino de Geometria. (Dissertação de Mestrado). Universidade Federal De Santa Catarina,

Florianópolis, Santa Catarina, Brasil.

Santos, J. E., \& Lando, J. C. (2020). Uma análise da geometria abordada nos livros didáticos durante o Movimento da Matemática Moderna: estudo baseado em dissertações e teses. Anais do ENAPHEM - Encontro Nacional De Pesquisa Em História Da Educação Matemática - ISSN 2596-3228, (5), 1-5. Disponível em: https://periodicos.ufms.br/index.php/ENAPHEM/article/view/10880.

Silva, J. C.D. (2014). As Transformações Geométricas nos currículos prescritos de matemática no Ensino Fundamental (1930-2010). (Dissertação de Mestrado). Universidade Anhanguera de São Paulo, São Paulo, Brasil. 
Thiago Neves Mendonça. (2016). Que Geometria ensinar as crianças em tempos de Matemática Moderna? (Dissertação de Mestrado). Universidade Federal de Juiz de Fora, Juiz De Fora, Minas Gerais, Brasil.

Valentim Júnior, J. L. (2013). A geometria analítica como conteúdo do ensino secundário: análise de livros didáticos utilizados entre a reforma Capanema e o MMM. (Dissertação de Mestrado). Universidade Federal de Juiz de Fora, Juiz de Fora, Minas Gerais, Brasil.

\section{CONTRIBUIÇÕES DOS AUTORES}

1 Sidnéia Almeida Silva: responsável pela pesquisa em nível de mestrado, que formulou o objetivo de compreender as propostas para o ensino de Geometria, produzidas em tempos do Movimento da Matemática Moderna, apresentadas nas pesquisas desenvolvidas no âmbito dos programas brasileiros de pós-graduação stricto sensu no período de 2000 a 2019. Atuou ativamente, desde a elaboração do projeto que originou a pesquisa, contribuindo mais ativamente na localização das fontes e análise de dados, estando presente nas discussões e demais etapas de escrita do artigo.

2 Larissa Pinca Sarro Gomes: orientadora da pesquisa e quem incentivou a escrita do artigo para a edição temática "História da educação matemática - contribuições para a formação de professores". Contribuiu de forma mais incisiva na elaboração da proposta do artigo, com a seleção do aporte teórico, que vem conduzindo a pesquisa em andamento. Participou e esteve presente em todas as etapas de produção do artigo.

3 Martha Raíssa lane Santana da Silva: coorientadora da pesquisa que deu origem ao artigo. Participou das discussões para entendimento das contribuições do aporte teórico para a pesquisa. Apoiou desde o planejamento, contribuindo com resumo, a revisão do texto em língua inglesa e espanhola, os aspectos metodológicos e as considerações finais. 